\title{
Serum IgG and Renal Transplantation
}

\author{
G. KU， Z. VARGHESE， O. N. FERNANDO， R. BAILLOD， J. P. HOPEWELL， J. F. MOORHEAD
}

British Medical fournal, 1973, 4, 702-707

\section{Summary}

In 57 patients with renal allografts the prolonged administration of prednisolone $\geqslant 1 \mathrm{mg} / \mathrm{kg} / \mathrm{day}$ and azathioprine $\geqslant 3 \mathrm{mg} / \mathrm{kg} / \mathrm{day}$ caused a significant and persistent fall in serum IgG at all levels of creatinine clearance. The fall in IgG was more striking when creatinine clearance was below $25 \mathrm{ml} / \mathrm{min}$. At lower doses of azathioprine and prednisolone serum IgG fell when the creatinine clearance was less than $35 \mathrm{ml} / \mathrm{min}$, the degree of recovery towards normal being dependent on creatinine clearance and dosage. Post-transplant haemodialysis decreased the depression of IgG, and patients with immediately functioning grafts had minimal IgG depression. An inverse relation between IgG and IgM was observed in some patients. Severe infections and toxicity were associated with the greatest reduction in IgG; leucopenia and thrombocytopenia were not consistently reliable guides to toxicity. The deaths of four patients $(7 \%)$ were associated with severe infections. Falls in IgG were not related to the rejection process. IgG measurement should be used as a guide to immunosuppression and toxicity in renal allograft patients.

\section{Introduction}

The lack of specificity of the immunosuppressive agents in patients with renal allografts often gives rise to fatal infections and toxicity (Hill et al., 1967). The toxic effects of azathioprine are generally monitored by the peripheral white blood and platelet counts. However, the concomitant use of prednisolone, with its effects on the bone marrow, may make the circulating white cell count difficult to interpret (Woodruffe et al., 1969). The finding of hypogammaglobulinaemia and Pneumocystis carinii infection in a renal allograft patient prompted a serial study of serum immunoglobulins in other renal transplant patients. Previous studies of immunoglobulins in patients with renal allografts over the short term showed inconsistent results (Zuhkle et al., 1967; Levine et al., 1970; Rodriguez-Iturbe et al., 1971; Wells and Jeremy, 1971). In the present study the follow-up of serum immunoglobulins was prolonged. The pattern of change was evaluated and related to the dosage of immunosuppressive agents, the creatinine clearance, the white cell and platelet counts, and the clinical events including rejection, infection, and other toxic manifestations.

\section{Patients and Methods}

Fifty-seven patients on the renal failure programme (Moorhead et al., 1970) were selected for cadaveric renal allografts. Only

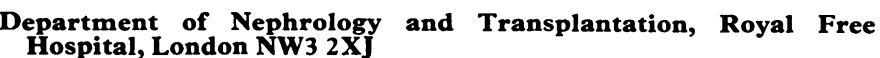

G. KU, M.B., M.R.C.P., Research Fellow, (Present address: Medical Unit II, General Hospital, Outram Rd., Singapore)

Z. VARGHESE, M.SC., Chief Biochemist

O. N. FERNANDO, F.R.C.S., Lecturer in Surgery

R. A. BAILLOD, M.B., B.S., First Assistant

J. P. HOPEWELL, F.R.C.s., Consultant Urologist

J. F. MOORHEAD, M.B., F.R.C.P., Director
}

one patient did not receive maintenance haemodialysis before transplantation. No patient had a splenectomy or thymectomy. Of the 57 patients 25 were selected for study on the basis of completeness of follow-up and graft function for more than one month. Twenty patients had first, and five had second grafts. There were 11 men and 14 women (age range from 20 to 57 years). The duration of follow-up varied from two to 36 months (mean 17.4 months) (table I). In cases $2,3,6,12$, and 13 pretransplant serum immunoglobulins were determined in retrospect from stored sera; post-transplant studies were started from the eighteenth, seventeenth, twelfth, tenth, and eighth month after operation respectively.

Donor selection, preservation of donor kidneys, and histocompatibility testing were consistent, and have been previously described (Festenstein et al., 1971). Post-transplant haemodialysis was carried out in all these patients with Kiil dialysers. The number of haemodialyses that the patients required before the creatinine clearance reached $10 \mathrm{ml} / \mathrm{min}$ varied from 1 to 41 , and the time taken to achieve this level of renal function was up to 78 days (tables I and II). Haemodialysis frequency varied between 1 and 5 times a week, depending on the clinical state of the patient, each session lasting from six to eight hours.

\begin{tabular}{|c|c|c|c|c|c|c|}
\hline $\begin{array}{l}\text { Series } \\
\text { No. }\end{array}$ & $\begin{array}{l}\text { Case } \\
\text { No. }\end{array}$ & Age & Sex & $\begin{array}{c}\text { Lowest Serum } \\
\text { IgG in mg/100 ml } \\
\text { ("., of } \\
\text { Pretransplant } \\
\text { Level*) }\end{array}$ & 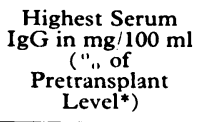 & $\begin{array}{l}\text { Duration } \\
\text { of } \\
\text { Follow-up } \\
\text { (months) }\end{array}$ \\
\hline $\begin{array}{r}1 \\
2 \\
3 \\
4 \\
5 \\
6 \\
7 \\
8 \\
9 \\
10 \\
11 \\
12 \\
13 \\
14 \\
15 \\
16 \\
17 \\
18 \\
19 \\
20 \\
21 \\
22 \\
23 \\
24 \\
25\end{array}$ & $\begin{array}{r}2 \\
3 \\
6 \\
12 \\
13 \\
15 \\
17 \\
18 \\
21 \\
23 \\
24 \\
27 \\
28 \\
29 \\
30 \\
31 \\
33 \\
35 \\
36 \\
39 \\
43 \\
44 \\
54 \\
55 \\
56\end{array}$ & $\begin{array}{l}48 \\
41 \\
30 \\
26 \\
37 \\
30 \\
33 \\
43 \\
57 \\
23 \\
43 \\
29 \\
23 \\
35 \\
43 \\
41 \\
42 \\
48 \\
20 \\
45 \\
46 \\
46 \\
25 \\
39 \\
50\end{array}$ & $\begin{array}{l}F . \\
M . \\
M . \\
M . \\
F . \\
F . \\
M . \\
F . \\
\text { M. } \\
\text { F. } \\
\text { M. } \\
\text { F. } \\
M . \\
\text { M. } \\
F . \\
\text { M. } \\
F . \\
F . \\
M . \\
M . \\
F . \\
F . \\
F . \\
F .\end{array}$ & $\begin{array}{l}750(51) \\
620(41 \cdot 6) \\
500(33) \\
780(53) \\
480(31) \\
560(38) \\
800(73) \\
700(64) \\
640(51) \\
720(41) \\
840(47) \\
450(45) \\
520(47) \\
720(80) \\
500(50) \\
460(19) \\
680(57) \\
580(50) \\
1,100(48) \\
760(49) \\
500(33) \\
740(74) \\
315(29) \\
430(44) \\
410(41)\end{array}$ & $\begin{array}{l}1,950(123) \\
1,300(87) \\
1,050(78) \\
1,800(121) \\
980(66) \\
1,170(79) \\
1,700(156) \\
1,500(138) \\
1,200(96) \\
1,400(80) \\
1,850(102) \\
900(90) \\
1,500(136) \\
1,400(155) \\
2,400(240) \\
2,000(83) \\
1,650(138) \\
1,400(121) \\
1,600(70) \\
1,600(103) \\
1,130(75) \\
1,700(170) \\
900(83) \\
1,120(114) \\
950(95)\end{array}$ & $\begin{array}{r}25 \\
26 \\
28 \\
34 \\
24 \\
36 \\
30 \\
26 \\
19 \\
25 \\
15 \\
12 \\
24 \\
21 \\
18 \\
18 \\
18 \\
15 \\
12 \\
16 \\
6 \\
12 \\
2 \\
3 \\
3\end{array}$ \\
\hline
\end{tabular}

*Pretransplant $\mathrm{IgG}=100 " \mathrm{*}$.

\section{IMMUNOSUPPRESSION}

Bolus intravenous injections of azathioprine $200 \mathrm{mg}$ and prednisolone $200 \mathrm{mg}$ were given postoperatively. Thereafter, the patients were given azathioprine by mouth. The dose of azathioprine was controlled in the last 43 patients (table III, group B) by keeping serum IgG above $500 \mathrm{mg} / 100 \mathrm{ml}$, the white blood count above $5,000 \mathrm{~mm}^{3}$, and platelet count above $150,000 \mathrm{~mm}^{3}$. The maintenance dose of azathioprine three months after the transplantation was $50-150 \mathrm{mg} /$ day. Prednisolone was given by mouth in a dose of $100 \mathrm{mg} /$ day, reducing to $30 \mathrm{mg} /$ day by the end of the first month. The dose was further reduced by $2.5 \mathrm{mg}$ weekly until a maintenance dose of $10-15 \mathrm{mg} /$ day was reached. Antilymphocyte globulin was not used. 
TABLE II-Outcome of 57 Consecutive Renal Allografts from March 1968 to February 1973

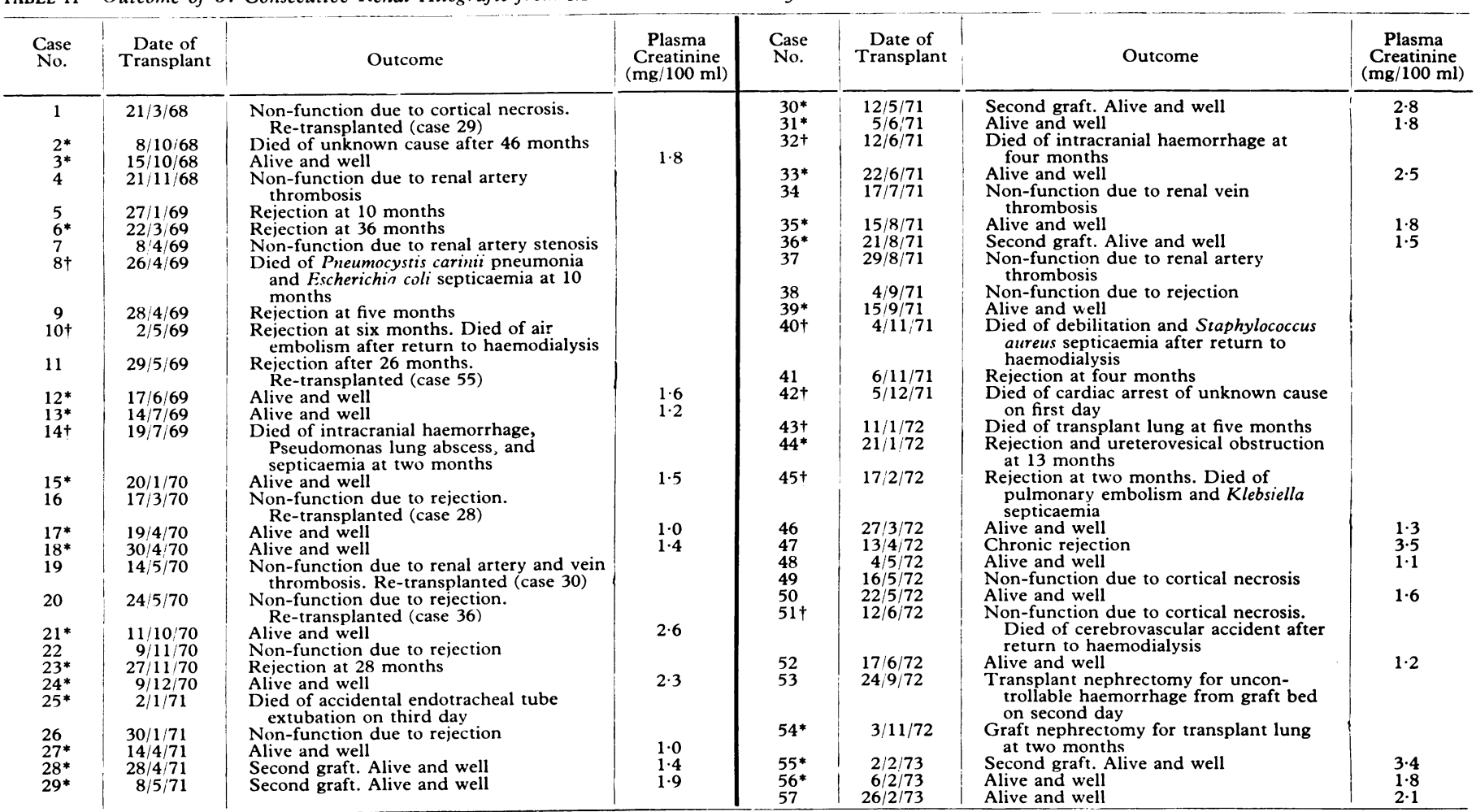

*Patients included in this study.

tDied.

TABLE III-Summary of Outcome of 57 Consecutive Renal Allografts from March 1968 to February 1973

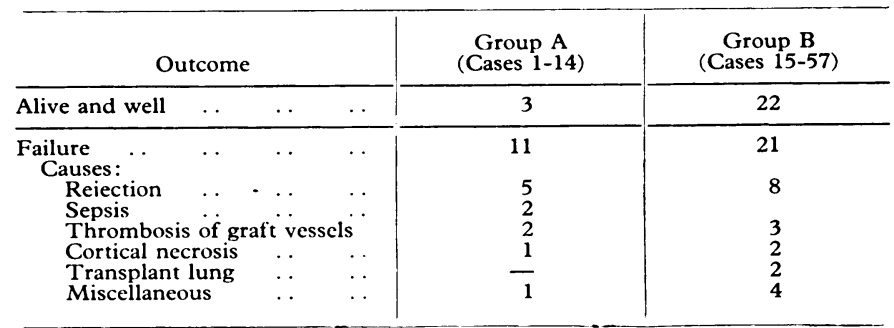

During the initial 18 months of the transplantation programme azathioprine $200-300 \mathrm{mg}$ and prednisolone up to $200 \mathrm{mg}$ daily was used in the first 14 patients (table III, group A) for two weeks or longer during obvious or suspected rejection episodes. These doses were not controlled by IgG monitoring.

In the last 43 patients (table III, group B), during a rejection episode, prednisolone was increased to $60 \mathrm{mg} /$ day until the episode was controlled and then gradually reduced to the maintenance level over four weeks. One or more of the following were given additionally to both groups of patients: intravenous hydrocortisone 100 to $400 \mathrm{mg} /$ day; actinomycin C $200 \mu \mathrm{g} /$ day intravenously for a maximum of three doses; and local graft irradiation, 200 rads for not more than three times. The dose of azathioprine was not altered during a rejection episode except in relation to the current serum IgG level, white blood cell count, and platelet count.

\section{POST-TRANSPLANT FOLLOW-UP AND ANALYSIS}

Serum IgG, IgA, and IgM were measured by the radial immunodiffusion technique (Mancini et al., 1965). Serum creatinine and creatinine clearance were measured by the Technicon AutoAnalyzer, and white blood cell and platelet counts by the Coulter counter. These tests were carried out daily for two weeks, on alternate days for the next two weeks, and at progressively longer intervals thereafter. Plasma urea and electrolytes, packed cell volume, liver function tests, 24-hour urinary protein, and other relevant tests were performed often. Patients were on a particular dosage of prednisolone and azathioprine for a minimum of three days preceding these tests. In cases where frequent alterations of immunosuppressive drugs were required the average dosages of the preceding three days were calculated. Serum immunoglobulin results were expressed as percentages of the pretransplant values. Prednisolone and azathioprine doses were classified into five groups (figs. 1 and 3), and a correlation was made between serum IgG

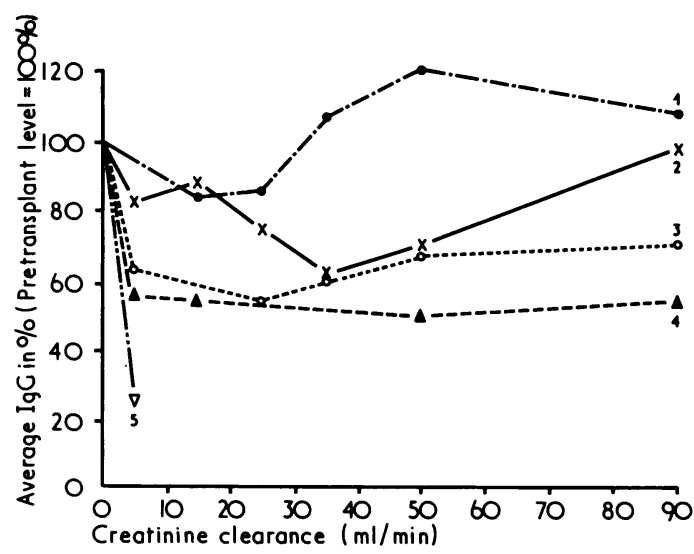

FIG. 1-Correlation of azathioprine and prednisolone dosages, creatinine clearance, and mean serum IgG in 25 renal allograft patients no longer requiring haemodialysis. Group $1=$ Prednisolone $0.25 \mathrm{mg} / \mathrm{kg} /$ day and requiring haemodialysis. Group $1=$ Prednisolone $0.25 \mathrm{mg} / \mathrm{kg} / \mathrm{day}$ and
azathioprine $1 \mathrm{mg} / \mathrm{kg} /$ day. Group $2=$ Prednisolone $0.5 \mathrm{mg} / \mathrm{kg} /$ day and azathioprine $1 \mathrm{mg} / \mathrm{kg} /$ day. Group $2=$ Prednisolone $0.5 \mathrm{mg} / \mathrm{kg} /$ day and
azathioprine $2 \mathrm{mg} / \mathrm{kg} /$ day. Group $3=$ Prednisolone $1 \mathrm{mg} / \mathrm{kg} /$ day and azathioazathioprine $2 \mathrm{mg} / \mathrm{kg} /$ day. Group $3=$ Prednisolone $1 \mathrm{mg} / \mathrm{kg} /$ day and azathio-
prine $3 \mathrm{mg} / \mathrm{kg} /$ day. Group $4=$ Prednisolone $1.5 \mathrm{mg} / \mathrm{kg} /$ day and azathioprine prine $3 \mathrm{mg} / \mathrm{kg} /$ day. Group $4=$ Prednisolone $1.5 \mathrm{mg} / \mathrm{kg} /$ day and azathioprine
$4 \mathrm{mg} / \mathrm{kg} / \mathrm{day}$. Group $5=$ Prednisolone $2 \mathrm{mg} / \mathrm{kg} / \mathrm{day}$ and azathioprine $5 \mathrm{mg} /$ $\mathrm{kg} /$ day. 
and the dosage in each group. The IgG results were obtained and plotted as the mean for each dosage group (fig. 3). Correlation with creatinine clearance was performed when patients no longer required post-transplant haemodialysis. The IgG results, classified on the basis of the prednisolone and azathioprine dosage, were grouped according to creatinine clearance: the mean IgG was then plotted for each level of creatinine clearance (fig. 1).

A longitudinal study was made of 15 patients (cases 6-20, table I) during the first 12 months after transplantation. The mean creatinine clearance and IgG is shown in fig. 2, and the coefficient of linear correlation and level of significance were calculated. Correlations of clinical events and serum immunoglobulin changes were made.

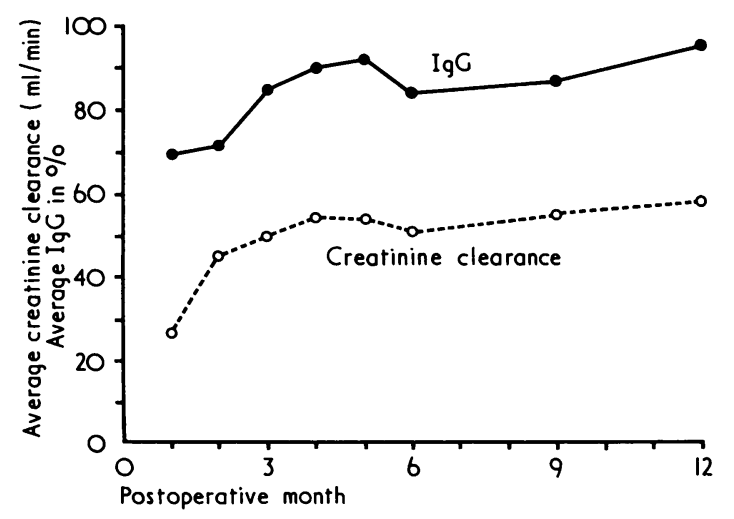

FIG. 2-Mean serum IgG and creatinine clearance in 15 renal allograft patients followed up for 12 months.

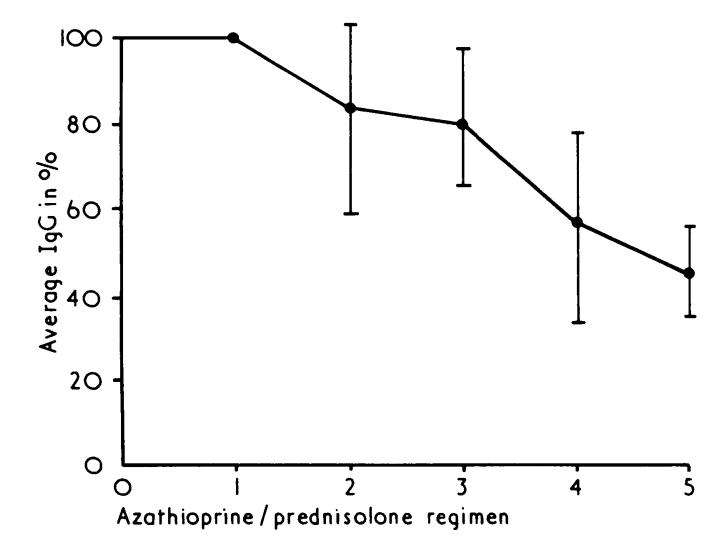

FIG. 3-Correlation of azathioprine and prednisulone dosages (mean serum IgG \pm 2 S.D.) in 25 renal allograft patients during period of post-transplant haemodialysis.

\section{Results}

The results of 57 consecutive renal cadaveric allografts are shown in tables II and III. Serum IgG, invariably depressed at some point in the postoperative course of all the patients studied, varied from $80^{\circ}{ }_{0}$, to $90^{\circ}{ }_{0}^{\circ}$ of pretransplant values (table I). The changes in IgG in patients who no longer required haemodialysis in the postoperative period are shown in fig. 1.

\section{GROUP 1}

Patients in group 1 (prednisolone $0.25 \mathrm{mg} / \mathrm{kg} /$ day and azathioprine $1 \mathrm{mg} / \mathrm{kg} /$ day) had a small fall of $17^{\circ} \%$ in the average serum IgG levels when the creatinine clearance was less than $25 \mathrm{ml} /$ min. IgG concentration returned to pretransplant level and above when the creatinine clearance exceeded $35 \mathrm{ml} / \mathrm{min}$.
GROUP 2

In group 2 (prednisolone $0.5 \mathrm{mg} / \mathrm{kg} /$ day and azathioprine $2 \mathrm{mg} / \mathrm{kg} /$ day) the maximal depression was $40^{\prime \prime}$ " when the creatinine clearance was below $35 \mathrm{ml} / \mathrm{min}$. As in group 1 improvement in creatinine clearance was followed by a gradual rise of serum IgG to the pretransplant levels.

\section{GROUP 3}

In group 3 (prednisolone $1 \mathrm{mg} / \mathrm{kg} /$ day and azathioprine $3 \mathrm{mg} /$ $\mathrm{kg} /$ day) serum IgG depression was more than $30 \%$, and this persisted at all levels of glomerular filtration rate.

\section{GROUP 4}

This phenomenon was even more obvious in patients in group 4 (prednisolone $1.5 \mathrm{mg} / \mathrm{kg} /$ day and azathioprine $4 \mathrm{mg} / \mathrm{kg} /$ day) when the depression approximated $50^{\circ}{ }^{\circ}$, though creatinine clearance levels reached $90 \mathrm{ml} / \mathrm{min}$.

\section{GROUP 5}

A profound fall of more than $70^{\circ} \%$ was observed in patients in group 5 (prednisolone $2 \mathrm{mg} / \mathrm{kg} /$ day and azathioprine $5 \mathrm{mg} / \mathrm{kg}$ / day).

The overall pattern of IgG change is exemplified by case 56 (fig. 4), where IgG fell to $40^{\circ}{ }_{\circ}(410 \mathrm{mg} / 100 \mathrm{ml})$ after pulse immunosuppressive therapy was given for the first rejection episode. The fall was less precipitous (IgG $580 \mathrm{mg} / 100 \mathrm{ml}$ ) after the second rejection when the creatinine clearance was $21 \mathrm{ml} / \mathrm{min}$. This patient showed an inverse relation between $\mathrm{IgG}$ and $\mathrm{IgM}$. The fall in IgG during immunosuppression was accompanied by a rise in IgM. Recovery of creatinine clearance plus reduction of immunosuppression was followed by a rise in IgG and a concomitant fall in IgM (fig. 4).

Escherichia coli urinary infection was present at the height of the IgG depression, but the association could be fortuitous. Leucopenia or thrombocytopenia was, however, absent.

The relation between the depression of serum IgG and mean creatinine clearance is also shown in fig. 2. Both these parameters were significantly related $(r=0.8663, P<0.01)$. Improvement of IgG followed gradual reduction of immunosuppressive drugs and was maximal when maintenance doses were reached towards the end of the 12 -month period. IgG depression was minimal in patients whose renal graft "worked on the table." This is illustrated by cases 17 and 45 (table II) in whom the creatinine clearance was $51.4 \mathrm{ml} / \mathrm{min}$ and 86.4 $\mathrm{ml} / \mathrm{min}$ respectively on the first postoperative day. The maximal IgG depression during that period was $12 \%$ for the first patient and nil for the second.

\section{EFFECT OF HAEMODIALYSIS}

At each dosage level of prednisolone and azathioprine in haemodialysed patients (groups 1 to 5 ) the mean serum IgG depression was much less than the corresponding value in transplanted patients with creatinine clearances of less than $10 \mathrm{ml} / \mathrm{min}$ (fig. 1) who no longer required haemodialysis. In group 5 the mean serum IgG was $55 \%$ of pretransplant values in patients during the haemodialysis period compared with the $25^{\circ} \%$ in those who no longer required haemodialysis.

\section{IgG AND INFECTION}

In the first 14 grafts high doses of immunosuppressive drugs were used (table III, group A). Two patients $(14.3 \%$ ) died of sepsis (cases 8 and 14, table II). In the last 43 cases (table III, 


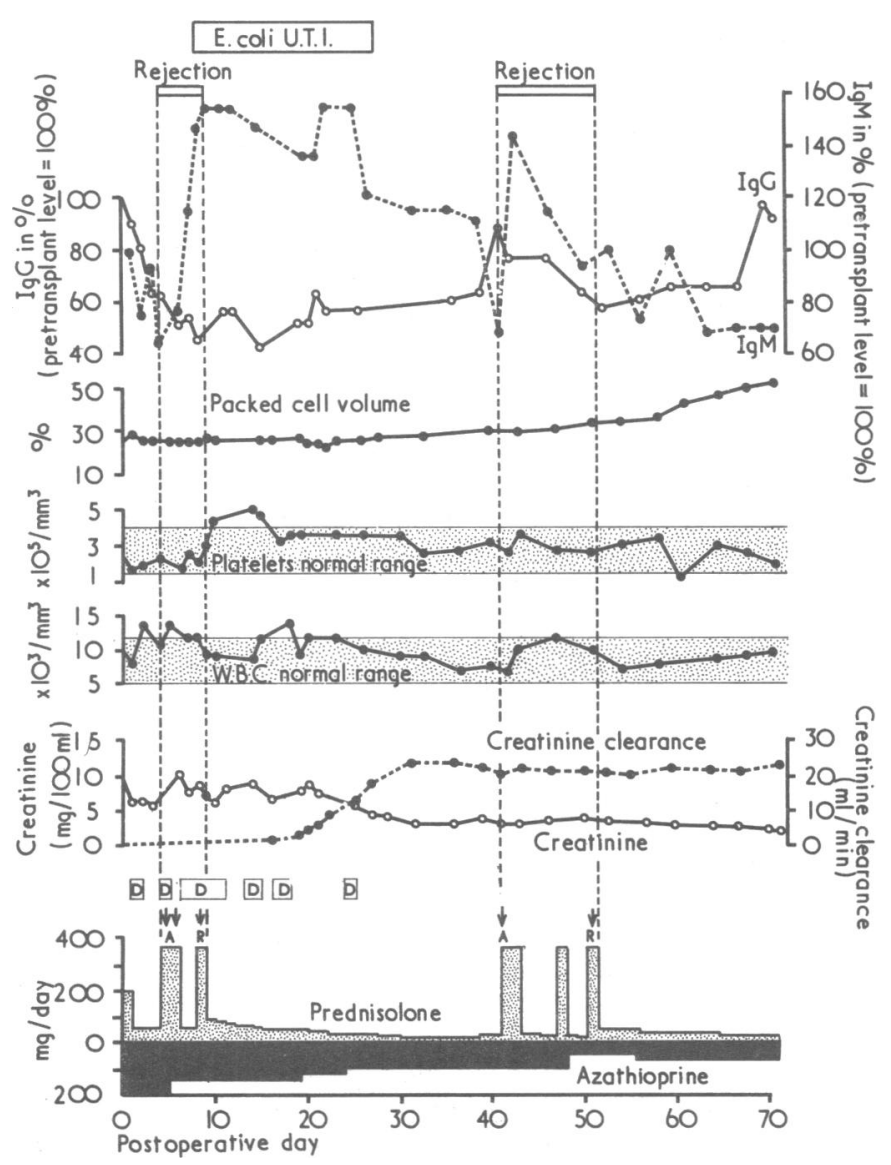
FIG. 4-Post-transplant course of case 54 (chronic glomerulonephritis).
$\mathbf{A}=$ Actinomycin. $\mathrm{R}=$ Deep $x$-ray graft irradiation. $\mathrm{D}=$ Haemodialysis. $A=$ Actinomycin. $R=$ Deep $_{\text {U.T. }} \boldsymbol{x}$-ray
U.T. = Urinary tract infection.

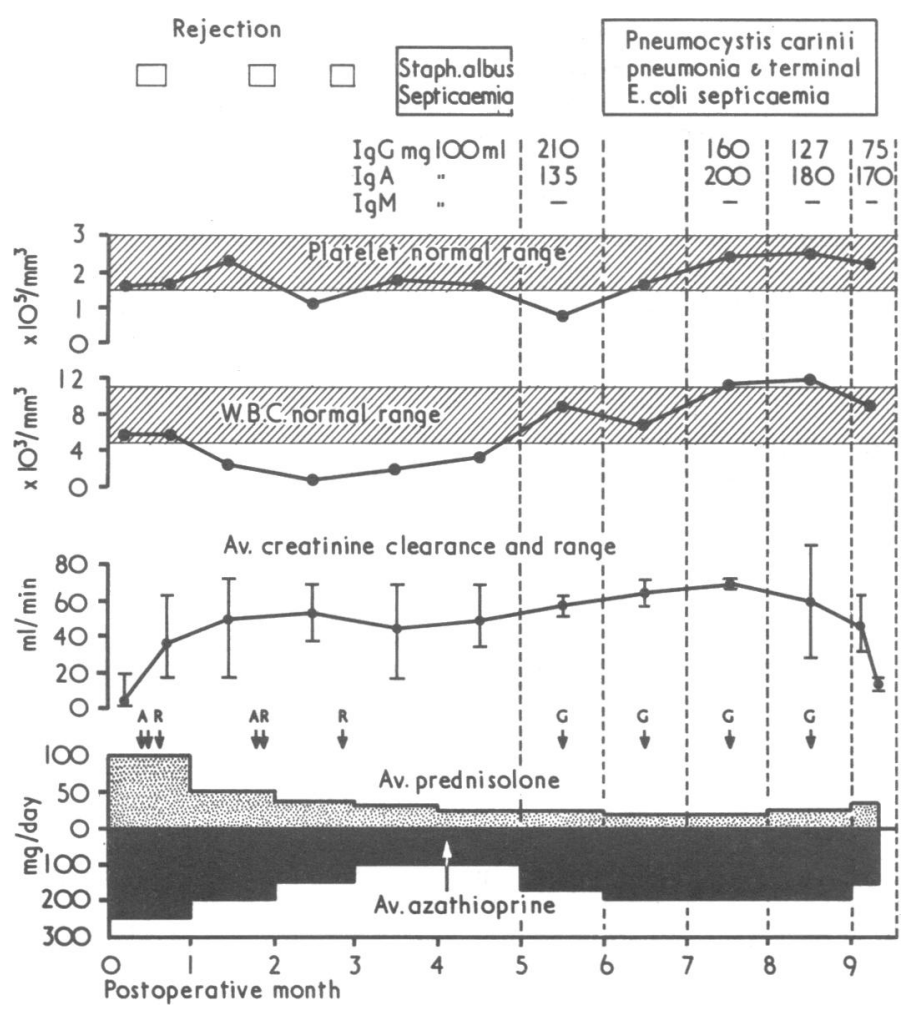

FIG. 5-Post-transplant course of case 8 (congenital hypoplastic kidneys) Association of hypogammaglobulinaemia and Pneumocystis carinii pneumonia. $\mathrm{G}=$ Gammaglobulin administration. group B), two patients (4.7\%) (cases 40 and 45) also died of sepsis. One (case 40) had gross debilitation and Staphylococcus aureus septicaemia (table II). The IgG level was $340 \mathrm{mg} / 100 \mathrm{ml}$. The other (case 45) died from pulmonary embolism and Klebsiella septicaemia, the IgG level being $440 \mathrm{mg} / 100 \mathrm{ml}$ (table II).

A low serum IgG was associated with Pneumocystis carinii pneumonia, diagnosed by lung biopsy, in case 8 (fig. 5). In this patient the average azathioprine dose was more than $3 \mathrm{mg} / \mathrm{kg} /$ day and prednisolone more than $0.5 \mathrm{mg} / \mathrm{kg} /$ day. The creatinine clearance remained at $50 \mathrm{ml} / \mathrm{min}$ until two days before death from $E$. coli septicaemia and respiratory failure. Total immunoglobulins were less than $500 \mathrm{mg} / 100 \mathrm{ml}$, IgA was normal, IgM was not measurable, IgG was very low at $210 \mathrm{mg} / 100 \mathrm{ml}$ and continued to decrease until it was $75 \mathrm{mg} / 100 \mathrm{ml}$, in spite of the administration of gammaglobulin by injection at monthly intervals. White cell count was normal during this period.

In case 54 (fig. 6) low IgG was associated with "transplant" lung. IgG depression after the first rejection was further aggravated after a second rejection episode. Coinciding with the maximum depression of IgG $(310 \mathrm{mg} / 100 \mathrm{ml})$ the patient developed a combination of pyrexia, extreme muscular weakness, tachypnoea, dyspnoea on the slightest exertion, hypoxia, and fluctuating renal function. Chest auscultation and radiography were uninformative. Respiratory function tests showed a restrictive type of defect with reduction in transfer factor. No systemic bacterial, viral, or fungal infection could be identified. Leucopenia was present. Cessation of immunosuppression, graft nephrectomy, and return to haemodialysis were resorted to. Her symptoms improved spontaneously. Gammaglobulin was given and serum IgG returned to normal.

\section{REJECTION AND MONITORING OF IMMUNOSUPPRESSION BY SERUM IgG}

Rejection caused loss of graft function in five of the 14 cases $(36 \%)$ in group A patients who received high dose immunosuppression initially and in eight of the 43 cases $(19 \%)$ in group B (table III). Thus lower doses of immunosuppressive drugs did not cause an increased incidence of graft rejection in the latter group.

\section{Discussion}

Various patterns of change in immunoglobulins have been described in renal allografts (Zuhlke et al., 1967; Levine et al., 1970; Rodriguez-Iturbe et al., 1971; Wells and Jeremy, 1971). In this study the only consistent trend detected was IgG depression. High dosage of immunosuppressive drugs, low levels of creatinine clearance, and haemodialysis were the major influencing factors. When the creatinine clearance was less than $25 \mathrm{ml} / \mathrm{min}$ depression of IgG was common at any dosage level of the immunosuppressive drugs, and became more severe at the higher dosages. Prolonged utilization of prednisolone $\geqslant 1 \mathrm{mg} / \mathrm{kg} /$ day and azathioprine $\geqslant 3 \mathrm{mg} / \mathrm{kg} /$ day caused a significant fall of serum IgG and a rise in creatinine clearance not matched by improvement in IgG concentration. Though in group 5 (fig. 1) there was insufficient data to correlate IgG and creatinine clearance beyond $5 \mathrm{ml} / \mathrm{min}$, the results in groups 3 and 4 suggest that the drastic fall would be sustained in spite of improvement in glomerular filtration.

Haemodialysis was associated with a fall in IgG which was smaller than expected. This phenomenon was conspicuous with higher doses of prednisolone and azathioprine. Ultrafiltration on haemodialysis did not cause a significant change in serum IgG level-a fact confirmed in a study of non-grafted haemodialysis patients ( $\mathrm{Z}$. Varghese and J. F. Moorhead, unpublished data).

Though IgG depression was most obvious in relation to graft rejection it was clear that rejection alone could not account for it, as the maximum fall of IgG occurred after the completion of 


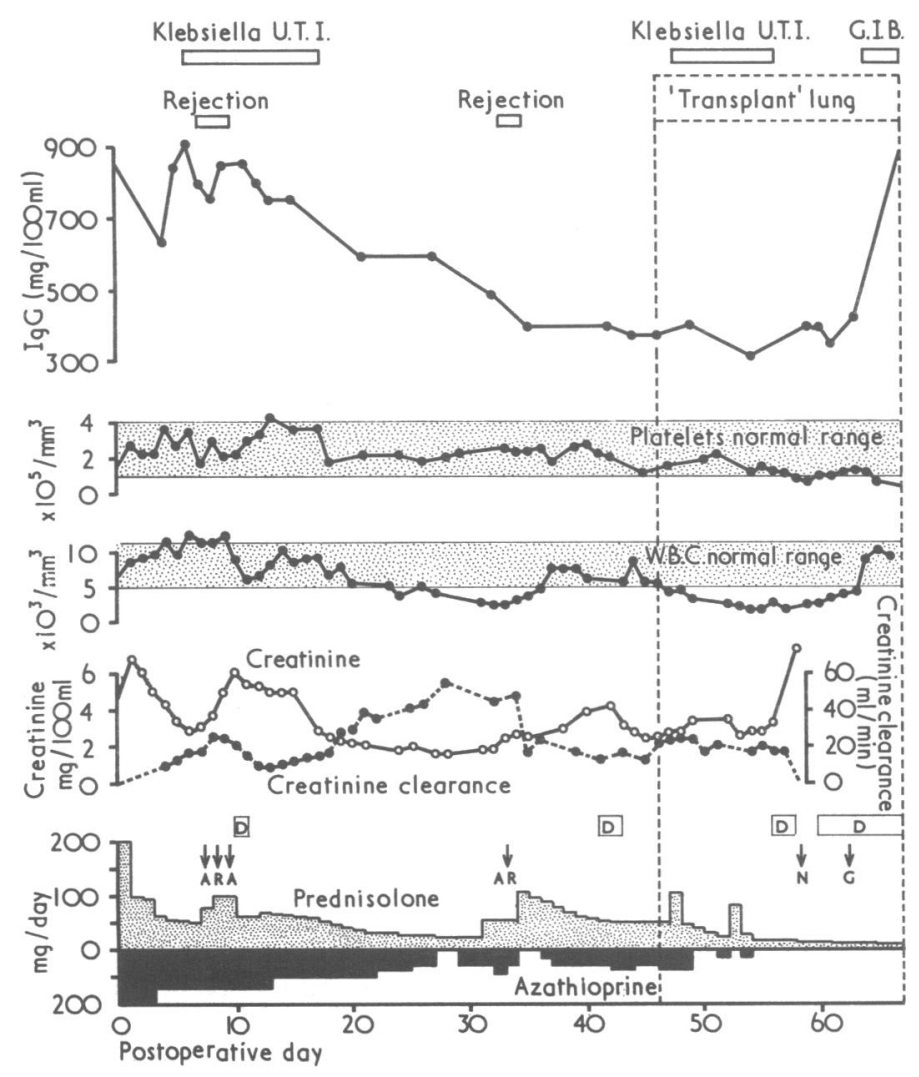

FIG. 6-Post-transplant course of case 54 (congenital hypoplastic kidneys). Association of low serum IgG and "transplant" lung. N= Graft nephrectomy. GIB = Gastrointestinal bleeding.

the pulse therapy. The degree of IgG depression appeared to be a function of the quantity and duration of immunosuppressive therapy, the current creatinine clearance, and the sensitivity of the patient to these drugs. The latter is illustrated in case 54 (fig. 6), in which IgG depression persisted in spite of improvement of creatinine clearance and reduction of immunosuppression.

Patients with established functioning renal allografts often had minimal or no IgG depression, as did those who achieved good diuresis and adequate creatinine clearance immediately after operation.

Though in cases $2,3,6,12$, and 13 high-dose immunosuppression was given initially, very low serum IgG was not seen since immunoglobulin studies for these patients were started from eight to 18 months after the operation-at a time when maintenance immunosuppression was used and renal function had become adequate and stable. In case 14 the patient died of sepsis, but serum IgG was not measured because its significance had not been appreciated at the time.

Haemodilution could not account for falls in serum IgG. Serial packed cell volumes, a good clinical indicator of acute changes in plasma volume, bore no relation to IgG concentration (fig. 4). Loss of immunoglobulins in the urine was found to be insufficient to account for the serum changes (Levine et al., 1970). The possible effect of blood transfusion could also be discounted, as these were given infrequently, and in any case bore no time relationship to the occurrence of IgG depression.

In studies of immune response in patients with autoimmune disease Swanson and Schwartz (1967) found that $65 \%$ of their patients had a significant selective fall of IgG during treatment with azathioprine accompanied by enhanced IgM synthesis. This phenomenon had been previously reported (Sahiar and Schwartz, 1965) in rabbits treated with mercaptopurine, and the authors suggested that the fall in IgG might cause IgM synthesis to be started through activation of a negative feedback process. Our finding of a reciprocal relation between serum IgG and IgM in some of our patients-for example, case 56 (fig. 4)-agrees with this observation. However, the fall in IgG cannot be attributed solely to azathioprine therapy, since prednisolone-a mainstay of treatment in transplantation-is capable of decreasing IgG concentrations in chronic active hepatitis (Mackay, 1968).

The effect of actinomycin C on serum IgG is not known, as it has always been used in combination with other drugs in these patients. Irradiation of the graft is unlikely to contribute to IgG change. The use of a combination of immunosuppressive drugs for conquering graft rejection made analysis of individual drugs difficult.

The association of low IgG and septic complications in renal allografts was reported by Harris et al. (1971) who found low IgG and leucopenia in six out of seven patients who had "late" infections after transplantation. The proximity of these to rejection and its treatment was emphasized. Anderson et al. (1973) found that azathioprine at $2 \mathrm{mg} / \mathrm{kg} /$ day was not associated with deaths due to infections in renal allograft patients. The data we have presented in this study show that at a dose of $2 \mathrm{mg}$ azathioprine $/ \mathrm{kg} /$ day and prednisolone $0.5 \mathrm{mg} / \mathrm{kg} /$ day serum IgG improves if creatinine clearance rises, but at a dose of azathioprine $\geqslant 3 \mathrm{mg} / \mathrm{kg} /$ day and prednisolone $\geqslant 1 \mathrm{mg} / \mathrm{kg} /$ day (fig. 1) IgG depression persists irrespective of glomerular filtration rate.

The complexity of the clinical transplant setting makes it difficult to attribute the lower incidence of fatal infections in the last 43 patients to the monitoring of IgG concentrations alone. Increased experience and awareness in the detection and management of complications are important contributing factors.

Our data are insufficient for meaningful statistical analysis, but we suggest that monitoring of IgG-particularly in the immediate post-transplant period when IgG might be expected to be low-is useful in modifying immunosuppressive dosage. Of 466 transplant deaths in Europe in 1970-1 (Brunner et al., 1972) no less than $38.1 \%$ were due to uncontrollable infection in the first two post-transplant months. The same study pointed out that $18 \%$ of cadaver kidney recipients in 1970-1 died of infections, and that infection was likely to remain the principal cause of death with present immunosuppressive regimens. Experience in the United Kingdom alone is similar, infection-the principal cause of mortality-accounted for $41 \%$ of deaths in renal allograft patients (Royal College of Physicians, 1972).

In comparison with leucocyte and platelet counts IgG measurement has proved to be a more consistent, reliable, and objective guide-probably of greater value in respect of azathioprine than prednisolone dosage.

Frequent measurements of serum IgG, in addition to haemotological counts should be carried out when the creatinine clearance is less than $25 \mathrm{ml} / \mathrm{min}$, and when high dose immunosuppression is used. Serum IgG should probably be kept above $500 \mathrm{mg} / 100 \mathrm{ml}$. Below this arbitrarily chosen concentration fatal sepsis occurred in three patients. Azathioprine of $\geqslant 3 \mathrm{mg} /$ $\mathrm{kg} /$ day and prednisolone $\geqslant 1 \mathrm{mg} / \mathrm{kg} /$ day should not be used for long periods, and frequent monitoring of toxicity at this dose level is essential.

Requests for reprints should be addressed to: Dr. J. F. Moorhead, Department of Nephrology and Transplantation, Royal Free Hospital, Lawn Road, Hampstead, London NW3 2XJ.

\section{References}

Anderson, R. J., Schafer, L. A., Olin, D. B., and Eickhoff, T. C. (1973) American fournal of Medicine, 54, 453.

Brunner, F. P., Gurland, H., Harlen, H., Scharer, K., and Parson, F. M. (1972). Proceedings of the European Dialysis and Transplant Association, IX, 3.

Festenstein, H. et al. (1971). Lancet, 2, 225.

Royal College of Physicians (1972). Report of the foint Committee on Maintenance Dialysis and Transplantation in the Treatment of Chronic Renal Failure. London, R.C.P. 

Harris, J. A., Diethelm, A. G., Mason, K. N., and Cobbs, C. G. (1971).
Alabama fournal of Medical Sciences, 8, 105.

Hill, R. B., Dahrling, B. E., Starzl, T. E., and Rifkind, D. (1967). American

Fournal of Medicine, 42, 327.
Levine, T. H., Merrill, D. A., Kohler, C. F., and Clamon, H. N. (1970).

Transplantation, 10, 141.
Mackay, I. (1968). Quarterly fournal of Medicine, 37, 379.

Mancini, G., Carbonara, A. O., and Hermans, J. F. (1965). Immunochemistry, 2, 235.

Moorhead, J. F., et al. (1970). British Medical fournal, 4, 83.
Rodriguez-Iturbe, B., Serrano, H., Garcia, R., and Gallegos, B. (1971). Transplantation, 12, 405.

Sahiar, K., and Schwartz, R. S. (1965). Fournal of Immunology, 95, 345. Swanson, M. A., and Schwartz, R. S. (1967). New England fournal of Medicine, 4, 163.

Wells, J. V., and Jeremy, D. (1971). Clinical Science, 40, 393.

oodruffe, M. F. A., Nolan, B., Robson, J. S., and MacDonald, M. K. (1969). British Medical fournal, 1, 6.

Zuhlke, V., Deodhar, S. D., Nakamoto, S., and Kolff, W. J. (1967). Transplantation, 5, 135.

\title{
Specific Lymphocyte Stimulation by Purified, Heat- inactivated Hepatitis-B Antigen
}

\author{
G. C. DE GAST, B. HOUWEN, H. O. NIEWEG
}

British Medical fournal, 1973, 4, 707-709

\section{Summary}

The ability of purified, heat-inactivated hepatitis-B antigen (HBAg) to stimulate sensitized lymphocytes in vitro was investigated with the lymphocyte stimulation test on lymphocytes from three groups of individuals. Stimulation was minimal in the lymphocytes of two out of 15 normal controls, whereas lymphocytes from nine out of 12 patients who had recovered from hepatitis $B$ showed stimulation, as did lymphocytes from five out of 12 laboratory technicians who had been regularly exposed to HBAg but who had no history of hepatitis or signs of it in the previous two years. No differences were observed in the responses to phytohaemagglutinin of lymphocytes from persons in the three groups. HBAg and HBAg inactivated by heat were shown in immunodiffusion to be immunologically identical. Inactivated HBAg stimulated antibody production in guinea-pigs. These findings suggest that not only humoral but also cell-mediated immunity might be induced by vaccination with purified, heat-inactivated HBAg.

\section{Introduction}

The role of humoral and cell-mediated immunity against hepatitis-B antigen (HBAg), formerly called Australia antigen or hepatitis-associated antigen (H.A.A.), in hepatitis B (serum hepatitis) is not at present clear. In many viral diseases elimination of the virus depends on intact cell-mediated immunity. This may also be important in the case of hepatitis B (Dudley et al., 1972 a). Cell-mediated immunity against $\mathrm{HBAg}$ in patients recovered from acute hepatitis $B$ has been studied with crude preparations of HBAg (Yeung Laiwah, 1971; Dudley et al., $1972 \mathrm{~b}$ ). In vitro lymphocyte stimulation and leucocyte migration inhibition in the presence of serum containing $\mathrm{HBAg}$ or of liver tissue homogenates, however, might be due to other antigens. A test for cell-mediated immunity which used purified HBAg would therefore be preferable.

\footnotetext{
University of Groningen, Department of Medicine, Division of Haematology, Groningen, Netherlands

Experiments have shown that $\mathrm{HBAg}$-positive serum is inactivated by heat (Krugman et al., 1970), and that active immunization with heat-inactivated serum provides some protection against hepatitis B infection (Soulier et al., 1972; Krugman and Giles, 1973). But whether the protection is due to humoral or cell-mediated immunity and whether the cellmediated immunity has been induced by the vaccination is uncertain. We report here our investigations of the antigenic properties in vitro of purified, heat inactivated $\mathrm{HBAg}$ in relation to humoral and to cell-mediated immunity.

\section{Materials and Methods}

In vitro lymphocyte stimulation tests were done on lymphocytes from three groups of persons seronegative for HBAg. The first group consisted of 15 persons with no history or signs of hepatitis (normal controls); the second consisted of 12 patients who had recovered from acute hepatitis $B$ (the interval between the disappearance of $\mathrm{HBAg}$ from their serum and the stimulation test varied from two to 72 weeks); and the third consisted of 12 laboratory technicians who had been regularly exposed to HBAg but who had shown no signs of hepatitis during a twoyear period of monthly screening for serum alanine transaminase, serum aspartate transaminase, and HBAg and who had no history of hepatitis.

HBAg (subtypes ad and ay) was isolated from pooled HBAgpositive sera by a three-stage method (Houwen et al., 1973). Sera diluted 1:3 with phosphate-buffered saline were ultracentrifuged at $350,000 \mathrm{~g}$ for six hours and the pellets resuspended and chromatographed on Sepharose 4B. HBAgpositive fractions were pooled and concentrated. Human serum proteins were removed from the solution by immunoadsorption, and shown by immunodiffusion to have been removed. Moreover, this purified HBAg preparation raised a monospecific antiserum against $\mathrm{HBAg}$ in guinea-pigs.

The purified $\mathrm{HBAg}$ was heated in a waterbath at $100^{\circ} \mathrm{C}$ for $3 \mathrm{~min}$. The HBAg titre had decreased by two dilution steps after the heating, probably owing to some precipitation and aggregation. $\mathrm{HBAg}$ was measured by radioimmunoassay (Ausria-125, Abbot Lab.). Hepatitis B antibodies (HBAb) were identified by counterelectrophoresis and reactions of identity by immunodiffusion.

For the lymphocyte stimulation tests suspensions of lymphocyte-monocytes were used which had been isolated from defibrinated blood by Ficoll-Isopaque gradient centrifugation according to the technique of Böyum (1968). Three hundred thousand lymphocytes were cultured in $12-75 \mathrm{~mm}$ Falcon tubes in $1 \mathrm{ml}$ MEM-Eagle with $20 \%$ autologous serum supplemented with penicillin $100 \mathrm{IU} / \mathrm{ml}$ and streptomycin $100 \mu \mathrm{g} / \mathrm{ml}$. Cultures 